\title{
Govier's "Informal Logic"
}

\section{J. ANTHONY BLAIR}

Centre for Research in Reasoning, Argumentation \& Rhetoric

University of Windsor

Windsor, $O N$

Canada N9B $3 P 4$

tblair@uwindsor.ca

\begin{abstract}
In this paper I review a number of Govier's criticisms of the standard view of logic at the time she was developing her views about the nature of logic as it applies to the critique of arguments in natural language and the development of ways to teach skills in such critique. I argue that the concept of informal logic has emerged at least in part from those criticisms and Govier's positive alternatives.
\end{abstract}

Résumé: Dans cet article je passe en revue un certain nombre de critiques de Govier sur l'approche standard de la logique au moment où elle développait ses idées sur la nature de la logique telle qu'elle s'applique à la critique des arguments exprimés dans un langage naturel et sur le développement des moyens d'enseigner des habiletés de construire une telle critique. J'avance que le concept de la logique non formelle a émergé au moins en partie de ses critiques et de ses alternatives positives.

Keywords: Trudy Govier, deductivism, formal logic, formalism, informal logic, philosophy of argument, theory of argument

\section{Introduction}

Counterfactual history is a mug's game; but consider this: if the First International Symposium on Informal Logic (FISIL, 1978) had not been held, informal logic would have taken a different path. For instance, the Informal Logic Newsletter would not have been founded (1978); the Second International Symposium on Informal Logic (1983) would not have been held (1983); the Newsletter would not have evolved into the refereed journal, Informal Log-

(C) J. Anthony Blair. Informal Logic, Vol. 33, No. 2 (2013), pp. 83-97. 


\section{J. Anthony Blair}

ic (1983); the Third International Symposium on Informal Logic (1989) would not have been held; the marked growth of research on informal logic topics to which the journal and the second two conferences gave outlet might not have occurred. But FISIL, which was co-chaired by R.H. Johnson and J.A. Blair, would not have been held had their textbook, Logical Self-Defense (1977) not been published, for, according to them, on its publication depended the impetus and confidence required to organize that first conference. ${ }^{1}$ However, Logical Self-Defense nearly didn't get published, for it was at first rejected and only a second round of reviewers convinced McGraw-Hill Ryerson to publish it. One of these secondround reviewers was Trudy Govier. Consequently, on one cut of the causal continuum, there is an argument that Govier must be regarded as one of the midwives of informal logic as we know it today. $^{2}$

Having helped to start the ball rolling, albeit unwittingly, Govier herself joined the enterprise enthusiastically and became one of informal logic's first theorists, publishing several early theoretical papers in the Newsletter and in Informal Logic (see 1979a, 1979b, 1980a, 1980b, 1981a, 1981b, 1983, 1985 for the earliest publications). She published the first theoretical book dealing with topics associated with informal logic, Problems in Argument Analysis and Evaluation (1987). And she has continued to publish reflections on informal logic theory over the past 30 years.

The question I address in this article is, "What is the content of informal logic for Trudy Govier?" By that I mean to investigate what features of her theoretical views reveal her conception of informal logic. The answer will not only emphasize the prominence Govier's views deserve, but also shed light on the nature of informal logic as a theoretical enterprise.

\footnotetext{
1 This is not to imply that Johnson and Blair had at that point a clear idea about what constitutes informal logic, but only to say that getting their textbook published and adopted was a necessary condition of their organizing that first symposium from which so much else followed.

2 The other second-round reviewer was Michael Gilbert, to whom the same remarks apply.
}

(C) J. Anthony Blair. Informal Logic, Vol. 33, No. 2 (2013), pp. 83-97. 
The answer developed in this article is that Govier's position on logic as it applies to natural language arguments is conditioned by her criticisms of a number of features of common assumptions about the nature of logic and its application to such arguments at the time of her writing. I consider these criticisms in turn.

\section{Problems with positivism}

"Positivism" is the label Govier gives to the position that all arguments are either deductive or inductive. This position, she argues,

is a prominent feature of logical positivism. It fits naturally into a positivist theory of knowledge within which knowledge must come either from logic and mathematics (sources of deductive arguments) or from the empirical sciences (sources of inductive arguments). (PAAE, p. 37) ${ }^{3}$

She notes that there are many versions of the distinction between deductive and inductive arguments (ibid.) and considers four of them.

First, if deductive arguments are those whose premises, if true, entail the conclusion and inductive arguments are those whose premises, if true, make the conclusion probable, then the distinction is exhaustive only for good arguments, for on this account bad arguments fall into neither category. Second, if deductive arguments are those whose premises, if true, entail the conclusion and inductive arguments are all the rest, then although the distinction is exhaustive, it is so at the cost of making all bad arguments inductive and, because so many different kinds of arguments are by definition inductive, also at the cost of the concept of an inductive argument having little coherence. Third, if deductive arguments are those of which it is claimed the premises entail the conclusion and inductive arguments are those of which it is claimed the premises

\footnotetext{
3 Page citations preceded by "PAAE" are from Govier's Problems in Analysis and Evaluation (1987).
}

(c) J. Anthony Blair. Informal Logic, Vol. 33, No. 2 (2013), pp. 83-97. 


\section{J. Anthony Blair}

make the conclusion more likely or probable, then, although there then can be bad as well as good arguments of both types, what is meant by "it is claimed" is ambiguous. If it refers to the intentions of the arguer, these can be difficult or impossible to know (and it requires the dubious presumption that the arguer does have one intention or the other). If it refers to the wording, context and nature of the argument itself, the clues offered by these factors are often perplexing so that the distinction can be difficult to apply to historical arguments. Fourth, if the deductive-inductive dichotomy does not apply to types of arguments, but instead to standards of appraisal, so that deductive standards test whether an argument's premise entail its conclusion and inductive standards test whether its premises make its conclusion probable, two problems arise. For one thing, the account does not help decide when it is appropriate to apply deductive standards and when it is appropriate to apply inductive standards. For another thing, there is in fact not a dichotomy of standards, but a plurality, for there are various versions of standards of both types and the account does not help decide which version to apply to any particular argument.

Govier notes that there are further difficulties of classification caused by incompletely expressed arguments. It is always possible to supply premises that will render the reconstruction of such an argument valid. So are all such arguments deductive? The various ways of making the distinction, she contends, provide no clear guidance about this question.

In general, Govier argues, the positivist dichotomy (which, she notes, has historical roots through Hume to Aristotle) has the result of overlooking the variety of arguments that have no deductive connection between premises and conclusion and make no claim to one, and to which a variety of standards are appropriate. For instance many normative arguments in ethics and elsewhere, or conceptual arguments typical in philosophy, or classificatory arguments in law - "which are not amenable to techniques of empirical confirmation ... and are not usually settled deductively" (PAAE, p. 53) —are overlooked. 


\section{Misapplications of rigour}

Already in 1980 Govier was arguing that the rigour characterizing formal logic is not attainable in the analysis of natural language arguments "in which someone tries to convince others (or himself) of the truth of a claim by citing reasons on its behalf" (PAAE, p. 4). Such arguments "are not amenable to fully precise treatment," she contends, for "they deal with [such things as] topics of controversy, disputed facts, plausible hypotheses, approximately correct analogies." To evaluate them, she asserts, "we must sort out ambiguities, see how diverse factors fit together, weigh pros and cons, consider the credibility of those on whom we may depend for testimony or expertise" (PAAE, p. 5). Using an argument by Alasdair MacIntyre against the need for a fully objective justification for beliefs about God as an example, Govier says that "to bend and twist this argument by analogy into a representation to which the rules of a formal system would apply would be relatively useless even if it were possible" (PAAE, p. 7).

Govier is not opposing formal logic. She is opposing the view that natural language arguments must be reformulated into the symbolic terms of some formal system if they are to be appropriately evaluated, and the related view that any method for analyzing and assessing natural language arguments that does not embody the rigour of formal logic is therefore inferior and not respectable.

\section{Overlooked types of reasoning and argument that are not deductive or inductive}

Govier was encouraged to reject what she regarded as the competing alternatives - deductivism ("...the view that all good arguments are deductively valid" PAAE, p. 82) and positivism (PAAE, p. 56 ) - by the analysis of case-by-case reasoning proposed by John 
Wisdom in the Virginia Lectures ${ }^{4}$ and the analysis of conductive reasoning proposed by Carl Wellman in Challenge and Response (1971).

Govier introduced the term 'a priori analogy' for the reasoning Wisdom termed 'case-by-case' - deciding a case by appeal to a similar case. Such analogical reasoning is non-inductive, for it does not settle differences about facts, differences that can be resolved by future observations (PAAE, p. 57). It does not issue in predictions, but in decisions (PAAE, p. 58). The underlying constraint of such reasoning is consistency. An argument by a priori analogy urges "a decision on a case based on the consideration of a closely similar one" on grounds of consistency (PAAE, p. 59).

Nor is reasoning by a priori analogy deductive. Attempts to reconstruct such arguments as elliptical deductions fail for several reasons. The universal generalization that has to be added to do so renders some of the original premises making the analogy redundant, thus destroying the analogy. Moreover, typically the required generalization is not known to be true, which is why the appeal to the analogy is made in the first case: were the generalization known, the analogy would not be needed. As well, such universal statements are usually uncertain, so the argument is weakened epistemically by their insertion (PAAE, pp. 59-60). Govier presents and analyzes several examples, and concludes that arguments by a priori analogy "are both real and epistemically legitimate" (PAAE, p. 65).

According to Wellman's notion of conductive reasoning, one draws or urges a conclusion about some individual case nonconclusively from one or more premises about the same case without any appeal to other cases. Typically there are several independently relevant premises that support the conclusion. They do not entail the conclusion, so the reasoning or argument is not deductive. Nor is it a case of confirming or disconfirming an hypothesis by instances,

\footnotetext{
${ }^{4}$ Although Wisdom delivered these lectures at the University of Virginia in 1957, they were not published until 1991 (see Wisdom 1991). However, Govier had early access to a copy.
}

(c) J. Anthony Blair. Informal Logic, Vol. 33, No. 2 (2013), pp. 83-97. 
and typically the reasons are cited to support a normative, conceptual of philosophical conclusion (PAAE, p. 66).

Wellman has idiosyncratic definitions of 'induction' and 'deduction,' which Govier does not endorse (PAAE, p. 69). She also rejects his requirement that the conclusions of conductive arguments must be about particular cases, arguing that arguments are possible in which separately relevant facts are used to support generalizations. But she endorses the features that there are arguments with separately relevant considerations that cumulate, often with both pros and cons having to be weighed, and that these make for a distinct class of arguments which are neither deductive nor inductive by any standard characterization of these categories.

\section{Deductivism and missing premises}

If deductivism - again, understood as the thesis that all [logically] good arguments are deductively valid (PAAE, p. 82) - were true, then it would provide a satisfactory solution to the problem of identifying when an argument is incomplete and how to formulate the missing ingredients when it is. In that case, an argument is incomplete if it is invalid as it stands. It can be made valid by being reconstructed with additional premises. If all of the premises are then true, the argument is sound; if some are false or implausible, the argument is poor. Govier thinks this neat solution to the problem of missing premises is riddled with problems.

One problem is the "curious" result that logic applies only to argument reconstruction, and has no role in its evaluation: "all reconstructed arguments are logically equal" (PAAE, p. 81). Another is that, unless qualified, a "deductivist policy on missing premises licenses overabundant expansion of arguments" (PAAE, p. 82). For one thing, there are an infinite number of possible missing premises for any argument, so that finding a flaw in any one candidate always fails to constitute definitive criticism of the argument. For another, since according to the deductivist doctrine all arguments that are invalid as stated are enthymemes, then "[o]n this view,

(c) J. Anthony Blair. Informal Logic, Vol. 33, No. 2 (2013), pp. 83-97. 


\section{J. Anthony Blair}

there are no fallacies (formal or informal), no analogies, no inferences to the best explanation, and so on" which is a result contrary to the tradition in logic and to recent work in the philosophy of science (PAAE, p. 82).

And a qualified deductivist policy on missing premises also faces problems. If some constraint on allowable missing premises is imposed, it is not clear what it should be. The associated conditional $^{5}$ can always be added to an invalid argument to render its reconstruction valid, but that is a redundant manoeuvre (PAAE, p. 88). If, to avoid that problem, some generalization of the associated conditional is used instead, the argument requires the further assumption that the selected generalization is the appropriate one for the argument. If premises other than the associated conditional or some generalization of it are supplied instead, the argument becomes "extremely cumbersome" (PAAE, p. 88). Govier concludes that deductivism "cannot offer a complete and satisfactory policy on missing premises." (PAAE, p. 88)

Govier considers whether a deductivist approach to the problem of missing premises might be followed without any commitment to the deductivist theory of argument. She sees two problems with such "heuristic deductivism." One is that without commitment to the deductivist theory of argument, there seems to be no good reason for deductivist reconstructions. The question, "Why add a gap-filler to make the argument deductively valid?" gets no answer. Second, all the above-mentioned problems confront heuristic deductivism no less than the theoretically committed version (PAAE, p. 89).

In sum, Govier concludes that deductivism does not help to solve the problem of how to reconstruct arguments with unexpressed premises. Consequently, one of the reasons for embracing deductivism as a theory of argument turns out to be without basis.

5 The "associated conditional" of an argument is a conditional proposition with the stated premises as its antecedent and the argument's conclusion as its consequent.

(C) J. Anthony Blair. Informal Logic, Vol. 33, No. 2 (2013), pp. 83-97. 


\section{Limits of formalism}

Govier observes that the following two positions are incompatible (PAAE, p. 203): logic is entirely formal logic, which is "the study of proofs and rules of inference in axiomatized formal systems" or else logic is partly formal logic but also the science of argument assessment that "will teach us how to understand and appraise the justificatory reasoning that people actually use." These alternatives are mutually exclusive because if logic is entirely formal, "it tells us only a small amount of what we need to know to understand and evaluate arguments." Govier has several reasons for decrying the limits of formalism in teaching us how to understand and appraise natural language argumentation.

The first limitation of formalism is that the interpretation of natural language texts is a "nonformal" process (see PAAE, pp. 204ff.). It requires, first, an understanding of the natural language in which the argument is expressed, which requires substantive background knowledge. It requires, second, identifying the sentences in texts that comprise an argument, which requires a sense for the "logical flow" of the discourse, and "the imputation of an intention to justify a claim or claims to an identified, or hypothetical, arguer." Pragmatic factors serve to distinguish argument from explanation, description, narration, exemplification, jokes, and so on. Third, "the need for argument, the presence of argument, and the direction of argument are determined" by an understanding of the context, of human purposes, and of background information. Fourth, once a text has been identified as argumentative, there is a need to identify which sentences are premises and which are conclusions, as well as to identify unstated premises or conclusionswhich often entails operations of deletion, rearrangement and addition. In sum, the mere identification of argument involves background knowledge, subtle verbal knowledge and a sense of logical direction, none of which can usefully be formalized.

A related limitation of formalism is that much of the task of appraising arguments (once identified and interpreted) is "preformal"- - that is, it would have to precede any attempt to formalize

(c) J. Anthony Blair. Informal Logic, Vol. 33, No. 2 (2013), pp. 83-97. 


\section{J. Anthony Blair}

the argument. How many premises there are, what the premiseconclusion structure of the argument is, and what kind of inferences they are (deductive of one sort or another, inductive, conductive, abductive, etc.) must be determined before formal logic can be used to determine whether the inferences of the argument(s) are valid. The interpretive and classificatory work that is entailed "presumes substantive knowledge, sensitivity to context, appreciation of nuances of meaning in context, recognition of subarguments, addition of implicit premises and conclusions and the classification of arguments and subarguments as being of one type or another" (PAAE, p. 210).

Govier uses the example of refutation by logical analogy, which, she argues, can be applied to nondeductive arguments as well as to deductive ones, to illustrate how a web of non-formal judgments is required to interpret arguments and how, at least typically, what it reveals as the structure of the argument is not formal "in any standard sense of the term" (PAAE, pp. 210ff.).

She also argues, using examples of fallacious "two wrongs make a right" arguments, that many fallacies rely on a mistaken material inference (PAAE, pp. 215-220). The analysis of the example requires, first, identifying the intended pattern of reasoning, and second, identifying the material inference that is used in it. This inference, like any statement, can be expressed in formal terms by supplying variables for its constants, but it doesn't follow that it can be assessed using formal logic, for the content of the material inference is substantive rather than logical. A defence of the judgment that the material inference used in a fallacious argument like a case of "two wrongs" or "ad hominem" is incorrect requires arguments about things such as the relevance of its general acceptance to an act's being justified, or the relevance of an assertor's character to the truth of what he asserts. Claims of consistency or fairness might have to be disputed. Substantive moral or epistemic judgments might be involved.

Related to the limits of formalism, in Govier's view, is the question of the necessity and limits of rules (PAAE, pp. 220ff.). It might seem that intelligent human activity (such as arguing and

(c) J. Anthony Blair. Informal Logic, Vol. 33, No. 2 (2013), pp. 83-97. 
argument interpretation and evaluation) is rule-following, that whenever there is a rule used it can be articulated, that if a rule can be articulated it can be formalized, and that if the rules of an activity can be formalized, a mechanical decision-procedure can be set out for the activity. Govier argues that the term 'rule' is vague, having a variety of possible senses, and that "any interpretation of rules and rule-following which will make it plausible to see all human intelligent activity as rule-governed [following ceteris paribus rules] will make it false that such rules can be formalized and programmed [requiring absolute and universal formal or material rules]." Govier cites with approval Kant's and Wittgenstein's arguments that rule-following cannot be itself regulated, but requires judgment; Carroll's Achilles/Toroise argument that "even when the mind is operating according to clearcut rules, such rules cannot all be made explicit in the context of use"; and Gödel's finding that "for any formal system of interesting complexity ... there are always statements expressible in the system and informally provable to be true, yet not provable according to the strict formal rules of the system itself."

In sum, Govier concludes, formal methods are not useful for identifying and understanding natural language arguments and their logical flow, and cannot suffice, and in any case are of limited use, for assessing their logical merits.

\section{Govier's informalism}

Govier's interest in argument theory is grounded in a practical objective. She wants theory that deals with arguments to serve the purpose of helping "to develop, articulate, and promulgate through teaching norms that people can reasonably and effectively use for the evaluation of arguments" (PA, p. 191) ${ }^{6}$. She wants “... the claims of informal logic and theory of argument to be practical and

\footnotetext{
6 Page citations preceded by "PA" are from Govier's The Philosophy of Argument (1999).

(C) J. Anthony Blair. Informal Logic, Vol. 33, No. 2 (2013), pp. 83-97.
} 


\section{J. Anthony Blair}

to convey skills which people with some training and normal intelligence can use to evaluate natural arguments presume this kind of pragmatic adequacy" (PA, p. 109). It is from this perspective that Govier considers the tools and attitudes of then contemporary logic and logical theory, and finds them wanting.

Anyone theorizing about the logic of arguments in the 1970s and 1980s, as Govier was doing, encountered a received opinion about the nature of logic, and of its application to arguments that consisted of a bundle of interconnected but distinguishable views. The limits of deductivism in theoretical explanations in science had been debated since the late 1960s (see Suppe 1988, p. 129), but the view that all arguments are either deductive or inductive (or else defective) was widely held. Logic, to philosophical or mathematical logicians, was by definition formal, that is, the study of formal structures, and accordingly logic's application to arguments was thus restricted to their formal properties. And the kind of rigour that formalism allows - the complete absence of vagueness and ambiguity and the exclusive focus on necessary consequence-was held up as a norm to be aimed for in philosophy in general (at least among analytic philosophers, as one of which Govier was trained), and certainly in logic.

As we have seen, Govier finds these prevailing assumptions - about the nature of argument, about deductive validity as the exclusive norm for inferences, about the domain of formal treatments, and about the ideal of logical rigour-all seriously wanting when it comes to their usefulness in the analysis and evaluation of natural language arguments used to persuade or justify. If logic is to be not only "the study of proofs and rules of inference in axiomatized formal systems," but also "the science of argument assessment ... that will teach us how to understand and appraise the justificatory reasoning that people actually use" (PAAE, p. 203), as Govier believed it should be, then the logic of natural language arguments must be informal in the respects specified by her critique of the conventional wisdom of the time. The recognition of arguments in texts and the analysis of their component elements and structures may legitimately rely on non-formal methods, including

(C) J. Anthony Blair. Informal Logic, Vol. 33, No. 2 (2013), pp. 83-97. 
such things as knowledge of the background and context of the discourse, understanding of linguistic and other communicative conventions, sensitiveness to ambiguity and vagueness, and a sense for the "logical flow" of reasoning and argument. It must be open to the possibility of legitimate inferences that are not deductively val$\mathrm{id}$, or statistical or enumerative inductions. If reconstructing arguments from texts by supplying premises not stated therein, one should be open to the possibility that the argument is non-deductive and non-inductive. Similarly, the evaluation of arguments is not to be limited to whether they are deductively valid or in a narrow sense of induction, inductively strong.

These prescriptions imply a range of theoretical questions that Govier regards as belonging to "the philosophy of argument" (see PA, p. 100). They include questions arising out of the different kinds and contexts of natural language arguments: the implications of the fact that such arguments have intended audiences, that they occur in typical contexts, that they presuppose background knowledge and understandings. They include questions about the kinds and nature of implication relations other then deductive validity or enumerative or statistical inference. They include the big question of what constitutes a logically good argument. Govier has in fact written on all of these topics. Her views about a priori analogy (e.g., PA, Ch. 9), about conductive arguments (e.g. PA, Ch. 10), about interactive vs. non-interactive audience arguments (e.g., PA, Ch. 11), and about what makes for a cogent argument (e.g., PA, Chs. 7, 12, 13) are all cases in point. 'Informal logic' is a term without precise denotation: it is one of those concepts that acquires its meaning over the history of its use. Govier sometimes refers to the field that deals with these questions as "informal logic" (e.g., PAAE, Ch. 10), sometimes as "theory of argument" (e.g., PAAE, Ch. 2), sometimes as "the philosophy of argument" (see PA). The definitional purist will want these distinguished, but Govier is concerned with answering the above questions, not with the definitions of these terms. My thesis is that Govier's particular answers to questions about "the nature of argument, the types of argument, and the nature and justifiability of norms for interpreting argu-

(c) J. Anthony Blair. Informal Logic, Vol. 33, No. 2 (2013), pp. 83-97. 
ment" (PA, p. 100) and for evaluating arguments, have contributed significantly to the substance of the concept of informal logic. What informal logic is for Govier is to a considerable extent what 'informal logic' means today. ${ }^{7}$

\section{References}

Govier, Trudy. (1979a). "Wellman`s Challenge and Response." Informal Logic 2(2).

Govier, Trudy. (1979b). "More on Deductive and Inductive Arguments." Informal Logic 2(3).

Govier, Trudy. (1980a). "Assessing Arguments: What Range of Standards." Informal Logic 3(1).

Govier, Trudy. (1980b). "Worries About Tu Quoque as a Fallacy." Informal Logic 3(3).

Govier, Trudy. (1981a). "Uncharitable Thoughts About Charity." Informal Logic 4(1).

Govier, Trudy. (1981b). "On Adler On Charity." Informal Logic 4(3).

Govier, Trudy. (1983). "Who Says There Are No Fallacies?" Informal Logic 5(1).

Govier, Trudy. (1985). "Logical Analogies." Informal Logic 7(1).

Govier, Trudy. (1987). Problems in Argument Analysis and Evaluation. Dordrecht: Foris.

Govier, Trudy. (1999). The Philosophy of Argument. Newport News, VA: Vale Press.

Suppe, Frederick. (1988). "A Nondeductivist Approach to Theoretical Explanation." In Adolf Grünbaum and Wesley C. Salmon (Eds.), The Limits of Deductivism, pp. 128-166. Berkeley: University of California Press.

${ }^{7}$ I thank Ralph Johnson for helpful criticisms of, and constructive suggestions for improvements to, earlier versions of this article.

(c) J. Anthony Blair. Informal Logic, Vol. 33, No. 2 (2013), pp. 83-97. 


\section{Govier's “Informal Logic" 97}

Wellman, Carl. (1971). Challenge and Response: Justification in Ethics. Carbondale and Edwardsville, IL: Southern Illinois University Press.

Wisdom, John. (1991). Proof and Explanation, The Virginia Lectures. Stephen F. Barker (Ed.). Lanham, MD: University Press of America.

(C) J. Anthony Blair. Informal Logic, Vol. 33, No. 2 (2013), pp. 83-97. 